\title{
AS CORRELAÇÕES ENTRE O TRATAMENTO JURÍDICO DA PROPRIEDADE INDUSTRIAL SOBRE FÁRMACOS ANTIRRETROVIRAIS E O DESENVOLVIMENTO NACIONAL
}

\author{
João Batista de Souza Leão Neto ${ }^{1}$ \\ Patrícia Borba Vilar Guimarães ${ }^{2}$
}

\begin{abstract}
RESUMO: Este artigo analisa as correlações do tratamento jurídico da propriedade industrial sobre fármacos antirretrovirais com o desenvolvimento nacional. Adota-se como método de abordagem o hipotético-dedutivo. A pesquisa realizada é predominantemente teórica, com objetivo explicativo e predominância da abordagem qualitativa. Utiliza-se, ainda, a pesquisa quantitativa, por meio de fontes secundários, a fim de se avaliar possíveis impactos do licenciamento compulsório de patentes. Validaram-se as seguintes hipóteses: o tratamento jurídico das patentes dos antirretrovirais é um instrumento para efetivação do princípio do desenvolvimento nacional; o desenvolvimento nacional fundamenta possível mitigação da propriedade industrial, para fim de licenciamento compulsório de patentes.
\end{abstract}

Palavras-chave: Propriedade industrial. Desenvolvimento. Patentes. Fármacos antirretrovirais.

\section{THE CORRELATIONS BETWEEN THE LEGAL TREATMENT OF INDUSTRIAL PROPERTY ON ANTIRETROVIRAL DRUGS AND NATIONAL DEVELOPMENT}

ABSTRACT: This article analyzes the correlations between the legal treatment of industrial property on antiretroviral drugs and national development. The approach method is the hypothetical-deductive. The research is predominantly theoretical, with an explanatory objective and predominance of the qualitative approach. Quantitative research is also used, using secondary sources, in order to assess the possible impacts of mandatory patent licensing. The following hypotheses were validated: the legal treatment of antiretroviral patents is an instrument for effecting the national development principle; the national development justifies possible mitigation of industrial property, for purpose of mandatory patent licensing.

Keywords: Industrial property. Development. Patents. Antiretroviral drugs.

\section{INTRODUÇÃO}

O tratamento jurídico adequado das patentes e de outras formas de proteção da propriedade intelectual desempenha essencial função no tocante ao fomento da pesquisa, do desenvolvimento e da inovação (PD\&I), operando efetividade ao disposto no art. 218 da

\footnotetext{
${ }^{1}$ Mestrando em Direito Constitucional pelo Programa de Pós-Graduação em Direito (PPGD) da Universidade Federal do Rio Grande do Norte (UFRN). Bacharel em Direito e em Ciência da Computação pela Universidade Federal do Rio Grande do Norte (UFRN). Servidor Público Federal da Justiça Eleitoral do RN. Lattes: http://lattes.cnpq.br/4646348680504529. Orcid: https://orcid.org/0000-0002-5675-6136. E-mail: joaoleao@ufrn.edu.br.

${ }^{2}$ Doutora em Recursos Naturais pela Universidade Federal de Campina Grande (UFCG). Mestre em Direito pela Universidade Federal do Rio Grande do Norte (UFRN). Advogada e Professora da Universidade Federal do Rio Grande do Norte (UFRN). Lattes: http://lattes.cnpq.br/3134219236556237. Orcid: https://orcid.org/0000-00019130-3901. E-mail: patriciaborb@gmail.com.
} 
Constituição da Federal - CF, tanto que se constitui em um dos direitos fundamentais, previsto no artigo $5^{\circ}$, XXIX, CF.

A propriedade industrial, por meio da concessão da patente é um dos mecanismos utilizados pelo Estado a fim de fomentar a PD\&I, uma vez que possibilita ao detentor da patente a exploração do mercado de forma exclusiva durante um determinado período, gerando um monopólio artificial com o intuito de que os custos e os riscos na pesquisa sejam compensados após a entrada do produto no mercado.

A proteção desse instituto exerce essencial função na descoberta de produtos farmacêuticos. Nesse setor, a importância do incentivo por parte do Estado se deve ao alto dispêndio de recursos econômicos que há na área de pesquisa, com o intuito de se desenvolver novos fármacos, sendo, então, esses recursos alocados responsáveis por parte significativa do custo final do produto.

Sem o incentivo do Estado, portanto, pode haver alocação insuficiente dos fatores de produção na área de PD\&I farmacêutica, o que pode ocasionar possível atraso científico e tecnológico no país, prejudicando, por conseguinte, o princípio constitucional do desenvolvimento nacional, em desacordo à norma preceituada no artigo $3^{\circ}$, II, da CF.

O tema proposto foi delimitado para se investigar o tratamento das patentes de fármacos antirretrovirais, por provocar, quando a sua exploração empresarial está protegida pelo regime de patentes, impactos substantivos na política pública de saúde, em decorrência da consequente elevação dos preços praticados no mercado.

O Estado brasileiro, cabe se destacar, está deveras vulnerável à oferta dos medicamentos antirretrovirais que são utilizados no tratamento da AIDS/HIV, por ter a obrigatoriedade de os fornecer, mediante o Sistema Único de Saúde (SUS), desde a entrada em vigor da Lei Federal nº 9.313/96.

Essa tendência à elevação nos custos dos medicamentos, quando se está diante da proteção pelo regime de patentes, decorre do fenômeno econômico que se denomina de "inelasticidade da demanda", haja vista que, pelo produto ser essencial para a subsistência humana, tem-se que o aumento do preço do fármaco não causa, na mesma proporção, a diminuição de sua demanda, o que incentiva a manutenção do preço elevado quando se está em uma estrutura de mercado do tipo monopólio.

O Governo Federal tem, em decorrência desse contexto, ameaçado em diversas oportunidades efetivar o licenciamento compulsório de patentes dos antirretrovirais, como forma de amenizar o alto preço praticado pelas empresas farmacêuticas, detentoras das patentes. Por meio do Decreto $n^{\circ} 4.830$, de 4 de setembro de 2003, foi autorizada a concessão, de ofício, 
do licenciamento compulsório para atendimento a casos de emergência nacional ou interesse público. Vindo, naquele ano, a conseguir a diminuição dos preços de antirretrovirais, tais como os de nome comercial Nelfinavir, Lopinavir, Efavirenz, Tenofovir e Atazanavir, em negociação com as farmacêuticas, após cogitar a possibilidade de se utilizar o licenciamento compulsório, para que os fármacos fossem produzidos por laboratórios estatais.

No ano de 2007, no entanto, não logrou, após negociações, reduzir substancialmente os custos do antirretroviral Efavirenz, cuja detentora da patente era a empresa Merck, o que levou o Governo Federal, por meio do Decreto ${ }^{\circ}$ 6.108, de 4 de maio de 2007, a decretar o licenciamento compulsório, sem exclusividade e para fins de uso público não-comercial, no âmbito do Programa Nacional de tratamento de portadores da AIDS/HIV, nos termos da Lei Federal $n^{\circ}$ 9.313/1996. Operando-se, pois, uma mitigação da propriedade industrial em função de um interesse social, que é amenizar os gastos, em especial os públicos, com a aquisição desses fármacos, de modo a possibilitar, dessa forma, maior acesso pela população.

A problemática se torna cada vez mais atual com a proliferação de novas infecções virais que assolam a população em todo planeta, como é o caso da atual pandemia denominada pela Organização Mundial de Saúde (OMS) de COVID-19, causada por uma nova cepa do Coronavírus.

Diante de tal cenário, foram apresentados recentemente 3 (três) Projetos de Lei na Câmara dos Deputados, que são os de número 1320/2020, 1462/2020 e 1184/2020, todos com o mesmo intuito de conferir celeridade na decretação do licenciamento compulsório quando se esteja diante de emergência de saúde pública, em nível nacional, como é o caso da atual pandemia, prevista na Lei $\mathrm{n}^{\circ} 13.979 / 2020$, que dispõe sobre as medidas para enfrentamento da emergência de saúde pública de importância internacional decorrente do coronavírus responsável pelo surto de 2019.

É dever do Estado a efetivação do direito à saúde, o que abarca o acesso aos medicamentos essenciais para tratamento de determinadas doenças pela população. É dever também, no entanto, o incentivo à pesquisa e à inovação, servindo, neste ponto, a propriedade industrial como fator fomentador, especialmente nas áreas de pesquisa em que há custos e riscos elevados.

Dirimir, pois, o aparente conflito não é trivial, uma vez que, neste sentido, tanto a proteção da propriedade industrial quanto sua mitigação buscam efetivar comandos constitucionais (artigos $6^{\circ}$ e 196, relacionados ao direito à saúde, em contraponto ao artigo $5^{\circ}$, XXIX, e artigo 218, relacionados à propriedade intelectual e ao incentivo ao desenvolvimento 
científico e tecnológico). Esses dispositivos constitucionais, cada qual com seu propósito, reverberam no desenvolvimento nacional, conferindo, pois, efetividade à norma disposta no artigo $3^{\circ}$, inciso II, da CF.

É primordial, assim, mensurar os possíveis impactos da propriedade industrial, no que concerne à proteção jurídica das patentes de fármacos, no fomento da pesquisa para o desenvolvimento de novos fármacos, como também na efetivação das políticas públicas de saúde, a fim de que, com os impactos mensurados, possa se buscar uma abordagem que confira maior efetividade ao desenvolvimento nacional.

Com base nisso, objetiva-se analisar as correlações do tratamento jurídico da propriedade industrial sobre fármacos antirretrovirais com o desenvolvimento nacional. Para a consecução desse objetivo, adota-se como método de abordagem o hipotético-dedutivo. Partese, então, de duas hipóteses a serem verificadas, que são: i) o tratamento jurídico das patentes dos antirretrovirais é um instrumento para efetivação do princípio do desenvolvimento nacional; ii) o desenvolvimento nacional fundamenta possível mitigação da propriedade industrial, para fim de licenciamento compulsório de patentes, conforme disposto no art. 71 da Lei $\mathrm{n}^{\circ}$ 9.279/2006.

A pesquisa realizada é predominantemente teórica, com objetivo explicativo e predominância da abordagem qualitativa. As técnicas de pesquisa utilizadas são a bibliográfica referenciada, entre livros, monografias, artigos científicos e teses, como também a documental, principalmente por meio da coleta de dados divulgados em relatórios por órgãos governamentais e organizações internacionais, buscando erguer-se sobre arcabouço teórico e prático atinente às áreas de Direito e Desenvolvimento (D\&D), Propriedade Industrial e Direito à Saúde. Há ainda, de forma mais pontual, a utilização da pesquisa quantitativa, por meio de fontes secundários, a fim de se avaliar os possíveis impactos do licenciamento compulsório das patentes no desenvolvimento socioeconômico nacional.

Dessa forma, o trabalho está estruturado de modo a se compreender sequencialmente: i) o que se entende por desenvolvimento nacional; ii) a importância da propriedade industrial na área farmacêutica; iii) a problemática que envolve a proteção das patentes dos antirretrovirais no Brasil e os reflexos no desenvolvimento nacional. Para, após isso, nas considerações finais, trazer os resultados alcançados, com ênfase na verificação das hipóteses levantadas, e proposições de trabalhos futuros.

\section{O DESENVOLVIMENTO NACIONAL}


A República Federativa do Brasil tem como um dos princípios fundamentais o desenvolvimento nacional, conforme disposto no artigo $3^{\circ}$, II, da Constituição Federal. Para efetivação desse princípio, o Estado brasileiro vem-se colocando como um agente fomentador do desenvolvimento, com mudanças em relação ao paradigma da forma de intervir na sociedade, vindo atualmente a se posicionar mais como ente regulador do que promotor direto do desenvolvimento, o que implica uma abordagem menos autoritária, com mais coordenação junto aos agentes privados.

O desenvolvimento vem sofrendo mudanças substantivas em seu significado com o transcorrer do tempo, com enfoque mais profícuo no campo econômico dado anteriormente, especialmente por economistas clássicos, vem-se transmudando nas últimas décadas para contemplar outros aspectos de cunho social e cultural, ampliando-se, pois, os pilares que lhe dão sustentação.

Um dos economistas clássicos que buscou analisar as razões pelas quais algumas nações se tornavam desenvolvidas, enquanto outras permaneciam ainda a se desenvolver, foi Adam Smith. Para o autor, o fator crucial para o desenvolvimento de uma nação seria o acúmulo de capital, o que possibilitaria o aumento da produtividade, com consequente aumento da renda. Pugnava, para isso, que deveria haver uma maior especialização no trabalho, de forma que cada indivíduo, ao se especializar, tenderia a desempenhar melhor as suas atividades (SMITH, 2006).

Da mesma forma, David Ricardo, outro economista clássico, ampliava as teses propostas por Adam Smith, levando-as para as relações econômicas internacionais. Sustentava que para uma nação se desenvolver seria necessário se especializar nas atividades econômicas em que havia uma vantagem comparativa em relação a outras, assim uma nação com muita terra fértil deveria se especializar na agricultura, ao passo que outra com mão de obra abundante deveria se especializar nas atividades intensiva em mão de obra, como era a tecelagem, por exemplo (RICARDO, 2018).

Do século XIX a meados do XX, havia, pois, uma tendência a se enfocar mais nos aspectos econômicos quando se deparava com o tema do desenvolvimento. Já a partir de meados do século $\mathrm{XX}$, há o debate crescente sobre as relações do direito com o desenvolvimento, vindo a se moldar, enquanto perspectiva teórica, o ramo do direito conhecido por "Direito e Desenvolvimento" (D\&D) (DAVIS; TREBILCOCK, 2008; TAMANAHA, 2009; TRUBEK; SANTOS, 2006; CAROTHERS, 2006).

O direito, então, começa a ser debatido como ramo imbricado no desenvolvimento, vindo a se formar correntes mais otimistas e outras mais pessimistas em relação ao direito como 
fator fomentador do desenvolvimento. Para a corrente otimista, o direito desempenha um papel essencial no desenvolvimento, defendendo-se a necessidade de se implementar reformas jurídicas nos países em desenvolvimento. São otimistas em três aspectos, por acreditar que: fatores específicos de um sistema jurídico desempenham função essencial na efetivação do desenvolvimento; uma reforma jurídica significativa é possível; conseguem identificar as reformas necessárias para se garantir o desenvolvimento (DAVIS; TREBILCOCK, 2008, p. 726).

A corrente pessimista, por outro lado, contesta que as reformas jurídicas são cruciais para o desenvolvimento, seja pelo pessimismo em relação ao papel do sistema jurídico no desenvolvimento, seja em relação às dificuldades que há na implementação dessa reforma, mormente as barreiras que há em cada sociedade ao se considerar os fatores históricos, econômicos, políticos ou culturais (DAVIS; TREBILCOCK, 2008, p. 26-45).

No último quartel do século XX, há uma guinada na forma de se entender o conceito de desenvolvimento, vindo a se estabelecer bases mais humanistas em seu significado. Um dos autores com grande contribuição neste sentido é Amartya Sen, para quem o desenvolvimento deve ser concebido como forma de se ampliar as liberdades humanas. Aborda o tema de forma a concebê-lo além da busca pela elevação da renda econômica, sopesando também fatores que ampliem as possibilidades de liberdade humana, considerando-se, então, o acesso às liberdades básicas instrumentais, como é o acesso à saúde, à educação, aos direitos civis, à participação política, à participação no mercado, à segurança, dentre outros. Em outros termos, os países devem buscar a remoção às restrições de liberdade, por meio de acesso às liberdades públicas positivas, fazendo com que surja maior oportunidade de participação do indivíduo na sociedade (SEN, 2010).

Há oportuna inovação no pensamento de Sen, ao conceber que o crescimento econômico, com ampliação da renda per capita de um país, por si só, não está vinculado à efetivação do desenvolvimento. É dizer, o crescimento econômico pode não operar a ampliação das liberdades públicas, vindo a incrementar, inclusive, o desnível social, quando se dá o aumento da desigualdade de renda (KANG, 2011).

É com base nessa concepção mais ampla de desenvolvimento, que Mahbub ul Haq com a colaboração de Amartya Sen criaram o Índice de Desenvolvimento Humano (IDH), em contraposição ao Produto Interno Bruto (PIB), que era o índice mais utilizado até então para mensurar o nível de desenvolvimento de um determinado país, porquanto o IDH contempla fatores relacionados ao acesso à saúde e à educação, além da renda. Atualmente, em decorrência de sua amplitude, é o índice utilizado para mensurar o desenvolvimento dos países pelo 
Programa das Nações Unida para o Desenvolvimento (PNUD). De acordo com dados extraídos do Relatório de Desenvolvimento Humano 2018, há ainda severas restrições das liberdades públicas no Brasil, com cerca de 7,4\% de brasileiros vivendo em situação de extrema pobreza (PNUD, 2018).

É salutar ressaltar que o desenvolvimento a ser perseguido é o nacional, conforme informa o artigo $3^{\circ}$, II, da Constituição Federal. O termo nacional fornece uma característica adicional à espécie de desenvolvimento que a nação deve buscar. De fato, conforme já pontuava Brian Tamanaha (2010), o D\&D deve se conformar aos aspectos sociais, culturais e políticos de cada local, de forma a frisar que a sociedade deve ser o centro de gravidade absoluto de D\&D. Da mesma forma, David Trubek e Marc Galanter (2009), em 1974, já criticavam o D\&D da forma como estava sendo concebido, de modo a pontuar que a principal falha do D\&D seria a crença de que um sistema jurídico, de um país desenvolvido, poderia ser facilmente implantado em países em desenvolvimento.

\section{A PROPRIEDADE INDUSTRIAL NA ÁREA FARMACÊUTICA}

Um dos propulsores do desenvolvimento é a inovação, que possibilita o aumento da produtividade econômica de um país, porquanto o incremento da ciência e da tecnologia resulta na alocação mais eficiente dos fatores de produção, o que garante ganhos de escala na produção (MENDES, 2012). A inovação, de fato, exerce uma função fundamental no fomento do desenvolvimento nacional, sendo obrigação do Estado a incentivar, conforme preceitua o artigo 218 da Constituição Federal.

Um dos mecanismos utilizados para esse fomento é a propriedade industrial, que visa a fomentar o desenvolvimento tecnológico e econômico do país, considerando-se para tanto o interesse social, conforme disposto no artigo $5^{\circ}$, XXIX, da Carta Magna, nos seguintes termos:

\footnotetext{
XXIX - a lei assegurará aos autores de inventos industriais privilégio temporário para sua utilização, bem como proteção às criações industriais, à propriedade das marcas, aos nomes de empresas e a outros signos distintivos, tendo em vista o interesse social e o desenvolvimento tecnológico e econômico do País.
}

O Brasil é um dos países que historicamente buscou proteger a propriedade industrial desde a origem, sendo signatário original da Convenção da União de Paris (CUP), celebrada no ano de 1880, promulgada por meio do Decreto Federal $n^{\circ} 75.572 / 1975$. De acordo com o disposto no artigo $1^{\circ}$ da convenção, propriedade industrial é o conjunto de direitos que compreende as patentes de invenção, os modelos de utilidade, os desenhos ou modelos 
industriais, as marcas de fábrica ou de comércio, as marcas de serviço, o nome comercial e as indicações de proveniência ou denominações de origem, bem como a repressão da concorrência desleal - que constituem suas ferramentas.

A legislação brasileira protege a propriedade industrial por meio das patentes, do desenho industrial, das marcas e das indicações geográficas, conforme regulamentado pela Lei Federal $n^{\circ}$ 9.279/96. O desenho industrial está disciplinado nos artigos 95 a 121, no qual é conceituado como "a forma plástica ornamental de um objeto ou o conjunto ornamental de linhas e cores que possa ser aplicado a um produto, proporcionando resultado visual novo e original na sua configuração externa e que possa servir de tipo de fabricação industrial". A marca, disciplinada no artigo 122, compreende "os sinais distintivos visualmente perceptíveis". A indicação geográfica, disciplinada nos artigos 176 a 182, é constituída pela "indicação de procedência ou a denominação de origem".

A patente, que faz parte do objeto analisado neste trabalho, é disciplinada nos artigos $6^{\circ}$ a 93 , concedida ao autor de invenção ou de modelo de utilidade. São patenteáveis a invenção "que atenda aos requisitos de novidade, atividade inventiva e aplicação industrial" e o modelo de utilidade que seja “objeto de uso prático, ou parte deste, suscetível de aplicação industrial, que apresente nova forma ou disposição, envolvendo ato inventivo, que resulte em melhoria funcional no seu uso ou em sua fabricação".

O exame dos depósitos e a concessão das patentes compete ao Instituto Nacional da Propriedade Industrial (INPI), autarquia federal vinculada ao Ministério da Economia, conforme Decreto $\mathrm{n}^{\circ}$ 9.660, de $1^{\circ}$ de janeiro de 2019. No caso das patentes para produtos e processos farmacêuticos, com a alteração promovida pela Lei Federal n. 10.196/2001, a concessão depende da prévia anuência da Agência Nacional de Vigilância Sanitária (ANVISA), autarquia sob regime especial, que tem por finalidade institucional promover a proteção da saúde pública.

O prazo de vigência de uma patente é disciplinado pelo art. 40, que dispõe que a "patente de invenção vigorará pelo prazo de 20 anos e a de modelo de utilidade pelo prazo 15 (quinze) anos contados da data de depósito". Há, no entanto, a ressalva que "o prazo de vigência não será inferior a $10(\mathrm{dez})$ anos para a patente de invenção e a 7 (sete) anos para a patente de modelo de utilidade, a contar da data de concessão, ressalvada a hipótese de o INPI estar impedido de proceder ao exame de mérito do pedido, por pendência judicial comprovada ou por motivo de força maior".

O que se questiona, no entanto, são as razões pelas quais se cria um monopólio artificial durante determinado período, mitigando os princípios da livre concorrência e da livre 
iniciativa, ambos pertencentes à Ordem Econômica Brasileira, expressos no artigo 170 da Constituição Federal. Conforme demonstrado por Menell e Scotchmer (2007), a necessidade de se proteger o invento por meio da patente se dá devido a um problema de alocação eficiente dos fatores de produção, que é uma falha de mercado, tendo em vista que o conhecimento intelectual pode ser apropriado sem custo caso seja disponibilizado o seu acesso, fazendo com que não haja incentivos para os agentes econômicos alocarem recursos nesse segmento.

Outro fator importante na proteção da patente é o fato de que o conhecimento é disseminado por meio da publicação periódica da Revista de Propriedade Industrial (RPI) do Instituto Nacional da Propriedade Intelectual (INPI). A publicação evita que as empresas detentoras de tecnologia não precisem de se resguardar por meio do segredo industrial, contribuindo, assim, para o fomento de futuras pesquisas correlacionadas.

A proteção da patente tem ainda mais proeminência no setor farmacêutico, haja vista os elevados custos despendidos na descoberta de novos fármacos, como também nos riscos de que a pesquisa não venha a entregar o resultado pretendido. Tendo isso em vista, a patente, ao conferir privilégio temporário de o titular atuar no mercado sob regime de monopólio, confere incentivo para o dispêndio de recursos na área de inovação do setor farmacêutico.

Para fim de ilustração, conforme colocado por Astrid Heringer (2001, p. 16), o custo para se pesquisar uma nova molécula com o intuito de se lançar um novo medicamento pode chegar a 350 milhões de dólares, podendo, ainda, se aguardar o período de 12 anos para se obter a liberação para comercialização. Ainda de acordo com Maria Helena Tachinardi (1993, p. 73), contribui para a elevação dos custos em P\&DI o fato de que para cada quatro mil moléculas pesquisadas apenas uma é aprovada para uso e, ainda, somente uma em cada quinhentos mil é utilizada em um novo fármaco.

Junto aos fatores apontados, tem-se ainda que o risco de se copiar uma tecnologia utilizada no desenvolvimento de um medicamento é sempre presente nessa indústria. Júlio Nogués (1990, p. 37) demonstrou que a fórmula utilizada para a elaboração dos fármacos pode ser facilmente copiada por meio de engenharia reversa, que consiste no método de se adquirir a tecnologia por qual um produto foi fabricado, analisando-se amostra do produto final.

\section{AS PATENTES DOS ANTIRRETROVIRAIS}

O direito à saúde, por sua vez, consubstanciado no Sistema Único de Saúde (SUS), previsto nos artigos 196 ao 200 da Constituição Federal, apresenta entre os seus princípios, a previsão do acesso aos serviços de saúde de forma integral e universal, devendo, pois, o Estado 
garantir a sua prestação. Em âmbito infraconstitucional, a Lei no 9.313/96 prevê que é dever do Estado a distribuição gratuita de medicamentos para tratamento dos portadores da AIDS/HIV, o que repercute sobremaneira nas despesas públicas.

Nesse ponto, é cabível pontuar que, no que se refere ao setor de medicamentos essenciais para o tratamento de doenças, ocorre o fenômeno que na economia se denomina de "inelasticidade da demanda", haja vista que, considerando-se o medicamento como essencial para a subsistência humana, verifica-se que o aumento do preço do fármaco não causa, na mesma proporção, a diminuição de sua demanda, o que incentiva a manutenção do preço elevado quando se está em uma estrutura de mercado do tipo monopólio (MANKIW, 2005).

O Brasil vem se destacando internacionalmente em relação ao tratamento da AIDS/HIV, mas, para tanto, faz-se necessário adquirir os medicamentos antirretrovirais que são produzidos, comumente, por laboratórios estrangeiros, vindo a serem vendidos internamente por preços elevados. Nesse escopo de tornar o tratamento mais amplo possível, o Governo Federal, em algumas situações, utilizou-se do licenciamento compulsório de patentes desses fármacos com o intuito de estimular a diminuição do preço, amenizando, assim, as despesas públicas incorridas.

O Acordo sobre Aspectos dos Direitos de Propriedade Intelectual Relacionados ao Comércio (conhecido por acordo TRIPs), do qual o Brasil é signatário (BRASIL, 2004), prevê diversos mecanismos de proteção à propriedade intelectual, tais como os direitos do autor, das marcas, das informações confidenciais, dos desenhos industriais e das patentes, com especial tratamento no que concerne aos fármacos.

Há, no entanto, no artigo 8 previsão de mitigação da propriedade ao permitir que os Estados adotem as medidas necessárias para proteger a saúde pública e a nutrição, como também para promover o interesse público, visando ao desenvolvimento social, econômico e tecnológico. Essa flexibilidade é de suma importância aos países em desenvolvimento, que dependem frequentemente da compra dos antirretrovirais, haja vista não deterem a tecnologia para empregar em sua produção.

Conforme pontua Amaral Júnior (2005), é possível que esses países estabeleçam restrições aos direitos dos detentores de patentes para reduzir o curso dos fármacos, a fim de possibilitar maior acesso por parte da população mais pobre, regulando-se, assim, o exercício dos direitos que a patente confere com o intuito de alcançar o interesse público.

Numa perspectiva de garantir o desenvolvimento nacional, no entanto, de modo a conferir aplicabilidade ao artigo $3^{\circ}$, II, da Constituição Federal, o incentivo à pesquisa e à inovação, como a efetivação do acesso aos medicamentos antirretrovirais, consignam o 
interesse público, surgindo, desta forma, um aparente conflito de normas constitucionais quando se depara o intérprete constitucional com a possibilidade de mitigar o direito de propriedade industrial a fim de se atender ao interesse social.

Em um aspecto infraconstitucional, conforme tutelado pela Lei Federal n ${ }^{\circ}$ 9.279/96, no artigo 71, o licenciamento compulsório pode ser decretado em decorrência do interesse público, o qual deve ser declarado por meio de ato do Poder Executivo Federal. O Decreto $\mathrm{n}^{\circ}$ 3.201/99 do Governo Federal regulamenta as condições pelas quais pode dar-se esse licenciamento, dispondo no $\S 2^{\circ}$ do artigo $2^{\circ}$ que "se consideram de interesse público os fatos relacionados, dentre outros, à saúde pública, à nutrição, à defesa do meio ambiente, bem como aqueles de primordial importância para o desenvolvimento tecnológico ou socioeconômico do País".

O dispositivo, conforme se percebe, não oferece parâmetros balizadores mais específicos na aplicação do interesse público ao pontuar que tanto a saúde pública quanto o desenvolvimento tecnológico ou socioeconômico são fatores a serem considerados, quando se depara com a aplicação do licenciamento compulsório de fármacos. Há de sempre se considerar que a mitigação do direito da propriedade intelectual pode justamente ocasionar prejuízos para o fomento tecnológico no país, prejudicando-se, consequentemente, o desenvolvimento de novos fármacos.

Torna-se essencial, com isso, analisar-se possíveis impactos socioeconômicos da, até então, única decretação do licenciamento compulsório, desde a vigência da Lei nº 9279/1996 (Lei da Propriedade Industrial). Por meio do Decreto Federal $n^{\circ}$ 6.108, de 4 de maio de 2007, concedeu-se o licenciamento compulsório, por interesse público, de patentes referentes ao Efavirenz, para fins de uso público não-comercial.

Esse antirretroviral é um dos medicamentos utilizados no tratamento do HIV/AIDS, faz parte do composto formado pelos antirretrovirais tenofovir (300mg), lamivudina (300mg) e efavirenz (600mg), denominado de “3 em 1” pelo Ministério da Saúde, está em distribuição pelo Sistema Único de Saúde (SUS) desde junho de 2014 (MINISTÉRIO DA SAÚDE, 2018).

Com relação ao efeito deletério no desenvolvimento nacional, ressalta-se a pesquisa quantitativa realizada por Thomas Kefas Dantas (2014, p. 143-146), o qual comparou o quantitativo das patentes internacionais registradas na modalidade PCT3 em todo o mundo com

\footnotetext{
${ }^{3}$ As patentes do tipo PCT são regulamentadas pelo Tratado de Cooperação de Patentes, do qual o Brasil é signatário. De acordo com a OMPI, mediante a apresentação de um pedido de patente internacional sob o PCT, os candidatos podem procurar simultaneamente a proteção de uma invenção em na maioria dos países do mundo. ORGANIZAÇÃO MUNDIAL DA PROPRIEDADE INTELECTUAL (OMPI). PCT - Sistema Internacional de Patentes. Disponível em: https://www.wipo.int/pct/pt/index.html. Acesso em: 20 abr. 2020.
} 
o quantitativo dessas mesmas patentes nas quais houve pedido de ingresso em fase nacional no Brasil. Considerou-se, para tanto, o código da classificação internacional de patentes A61P31/184, que identifica os compostos químicos ou preparações medicinais, anti-virais, específicos para o HIV, averiguando o número de depósitos no período de 2000 a 2013.

De acordo com os dados coletados, em 2008 somente 3 pedidos foram depositados no INPI, em relação aos 118 depositados via PCT. Em 2009, foram 4 pedidos, em relação aos 194 pedidos PCT no mesmo ano, e finalmente, em 2010, há apenas um pedido, em relação aos 136 pedidos via PCT. Em 2011, 2012 e 2013 não foram registrados pedidos de patentes (DANTAS, 2014, p. 146). O que se deduz dessa pesquisa é que, com a decretação do licenciamento compulsório no ano de 2007, houve um desestímulo às empresas internacionais para registrar as patentes relacionadas a antirretrovirais utilizados no tratamento do HIV/AIDS no Brasil, o que reverbera em impactos prejudicais sobre a produção e a distribuição local desses medicamentos.

Por outro lado, tem-se que a utilização do instituto mitigador da propriedade industrial foi eficaz no tocante à redução do preço do fármaco de nome comercial Efavirenz. Em 24 de abril de 2007, após o Governo Federal declarar o medicamento como de interesse público, por meio da Portaria MS n ${ }^{\circ}$ 886, de 24 de abril de 2007, do Ministério da Saúde, o laboratório Merck Sharp \& Dohme ofereceu redução de 30\% sobre o preço de US\$ 1,59 por comprimido de $600 \mathrm{mg}$, levando o valor unitário do produto a US\$1,11, o que não foi considerado satisfatório, já que havia proposta internacional de genérico no valor de US\$ 0,45 (RODRIGUES; SOLER, 2009, p. 555).

Por fim, após a decretação do licenciamento compulsório da patente, em 4 de maio de 2007, possibilitou-se a aquisição da versão genérica do mesmo fármaco pelo valor unitário de US\$ 0,46 , o que implicou uma redução de $71,35 \%$ no custo anual do tratamento. Estimou-se, ao final, uma redução de US\$ 30,6 milhões nos gastos com esse medicamento (RODRIGUES; SOLER, 2009, p. 556).

Abordando-se o princípio do desenvolvimento nacional como desenvolvimento multifacetário, no qual a saúde pública se apresenta como um dos pilares, em uma relação de interdependência com outras áreas, como é o desenvolvimento econômico, social e ambiental, temse que o que se busca é a ampliação do desenvolvimento humano, maximizando as capacidades de

\footnotetext{
${ }^{4}$ A Classificação Internacional de Patente (CIP) é utilizada para classificar patentes e modelos de utilidade de acordo com a área tecnológica de que pertençam. ORGANIZAÇÃO MUNDIAL DA PROPRIEDADE INTELECTUAL (OMPI). International Patent Classification (IPC). Disponível em: https://www.wipo.int/classifications/en/. Acesso em: 20 abr. 2020.
} 
cada indivíduo na integração da sociedade, conferindo, com isso, remoção de restrições que ameaçam as liberdades humanas, conforme pontuado por Armatya Sen (2010).

Percebe-se, assim, a incidência do desenvolvimento como pressuposto fundamental ao se cogitar a possível aplicação do licenciamento compulsório. O desenvolvimento deve ser visto, conforme já pontuado, como multifacetário, de modo a abarcar tanto os aspectos relacionados ao desenvolvimento econômico e tecnológico, quanto aos interesses sociais, o que compreende a viabilidade do acesso à saúde pública pela população mais vulnerável socioeconomicamente.

Diante das implicações socioeconômicas geradas pela norma, é necessário, pois, sopesar como as diversas áreas do desenvolvimento são afetadas pela possível mitigação da propriedade industrial, para que se possa avaliar a possibilidade da aplicação de um licenciamento compulsório sobre uma patente já concedida.

\section{CONSIDERAÇÕES FINAIS}

O presente trabalho analisou as correlações do tratamento jurídico da propriedade industrial sobre fármacos antirretrovirais com o desenvolvimento nacional. Para tanto, buscouse, preliminarmente, delinear o que é o desenvolvimento nacional, conforme disposto no art. $3^{\circ}$, III, da Constituição Federal. Observou-se que o desenvolvimento deve ser compreendido em uma perspectiva multidimensional, ou seja, além do mero desenvolvimento econômico por si só, buscando-se outras vertentes, como é o caso da observância da defesa do meio ambiente, nos termos do art. 170, VI, da CF, como também a efetivação dos direitos sociais, disposto no artigo $6^{\circ}$ da $\mathrm{CF}$. Nessa esteira, portanto, tanto o direito à saúde quanto o desenvolvimento tecnológico podem ser concebidos como faces do desenvolvimento que se complementam, sendo interdependentes.

Abordou-se, então, o conceito de desenvolvimento nacional como a busca pelo desenvolvimento multifacetário, buscando sempre a remoção das barreiras que impedem o pleno desenvolvimento humano. Cabe, ainda, destacar que o termo "nacional" também traz repercussão jurídica, uma vez que o desenvolvimento deve ser concebido considerando-se a realidade do país, com o sopesamento dos aspectos sociais, econômicos, políticos e culturais próprios da nação.

Em relação à aplicação da propriedade industrial, especificamente em relação à proteção jurídica conferida às patentes dos antirretrovirais, valida-se a primeira hipótese de que 
o tratamento jurídico das patentes dos antirretrovirais é um instrumento para efetivação do princípio do desenvolvimento nacional, porquanto constatou-se que:

i) é uma medida que fomenta a inovação das indústrias farmacêuticas, por possibilitar que investimentos maiores sejam direcionados na descoberta de novos fármacos, pois a patente, ao conferir privilégio temporário de o titular atuar no mercado sob regime de monopólio, confere incentivo para o dispêndio de recursos na área de inovação do setor farmacêutico;

ii) evita-se também que as empresas detentoras de tecnologia não precisem de se resguardar por meio do segredo industrial, contribuindo, assim, para o fomento de futuras pesquisas correlacionadas;

iii) ocasiona problemas sociais relacionados ao aumento dos custos dos medicamentos essenciais, em decorrência da estrutura de mercado do tipo monopólio criado por meio da concessão da patente.

iv) no caso dos fármacos antirretrovirais, há um forte impacto nas políticas públicas de saúde, decorrente do Programa Nacional de tratamento de portadores da AIDS/HIV, que obriga o Governo Federal a distribuir gratuitamente os medicamentos destinados ao tratamento, nos termos da Lei $n^{\circ}$ 9.313/1996.

Em relação à mitigação da proteção conferida às patentes, valida-se, também, a hipótese aventada de que o desenvolvimento nacional fundamenta possível mitigação da propriedade industrial, para fim de licenciamento compulsório de patentes, conforme disposto no art. 71 da Lei $n^{\circ}$ 9.279/2006, porquanto o Decreto no 3.201/99 do Governo Federal, que regulamenta as condições pelas quais pode aplicar-se esse licenciamento, dispõe no $\S 2^{\circ}$ do artigo $2^{\circ}$ que "se consideram de interesse público os fatos relacionados, dentre outros, à saúde pública, à nutrição, à defesa do meio ambiente, bem como aqueles de primordial importância para o desenvolvimento tecnológico ou socioeconômico do País".

Há, portanto, a incidência do desenvolvimento multifacetário, conforme propugnado, como fundamento para aplicação da norma, por contemplar fatores relacionados à busca do pleno do desenvolvimento humano, como é o caso da saúde pública, à nutrição, ao meio ambiente, ao lado do desenvolvimento tecnológico e socioeconômico.

A complexidade da aplicação recai, portanto, no sopesamento dessas áreas que são afetadas pela medida. No caso de um possível licenciamento compulsório da patente de um fármaco antirretroviral, os impactos a serem sopesados recaem primordialmente sobre a saúde pública e o setor de PD\&I das indústrias farmacêuticas.

Essa pesquisa, assim, pautou-se mais nos aspectos teóricos das imbricações da propriedade industrial com o desenvolvimento nacional, de modo que se propõe para fins de 
pesquisas futuras sobre o tema, a ampliação da aplicação de métodos empíricos, como é o caso da estatística, a fim de se mensurar os fenômenos sociais decorrentes da proteção da propriedade industrial e sua eventual mitigação, para atendimento a interesses sociais.

\section{REFERÊNCIAS}

AMARAL JÚNIOR, Alberto do. Licença compulsória e acesso a medicamentos nos países em desenvolvimento. Revista do Instituto dos Advogados de São Paulo, São Paulo, v. 8, n. 16, p. 11-23. 2005.

BRASIL. Decreto Federal $\mathbf{n}^{\mathbf{0}}$ 75.572, de 8 de abril de 1975. Promulga a Convenção de Paris para a Proteção da Propriedade industrial revisão de Estocolmo, 1967. 1975. Disponível em: https://www2.camara.leg.br/legin/fed/decret/1970-1979/decreto-75572-8-abril-1975-424105publicacaooriginal-1-pe.html. Acesso em: 20 maio 2019.

BRASIL. Decreto Federal no 1.355, de 30 de dezembro de 2004. Promulgo a Ata Final que incorpora os resultados da Rodada Uruguai de Negociações Comerciais Multilaterais do GATT. Disponível em: http://www.planalto.gov.br/ccivil_03/decreto/antigos/d1355.htm. Acesso em: 10 abr. 2019.

BRASIL. Lei $\mathbf{n}^{\circ}$ 9.279, de 14 de maio de 1996. Regula direitos e obrigações relativos à propriedade industrial. Disponível em: http://www.planalto.gov.br/ccivil_03/leis/19279.htm. Acesso em: 20 maio 2019.

BRASIL. Lei $\mathbf{n}^{0}$ 9.313, de 13 de novembro de 1996. Dispõe sobre a distribuição gratuita de medicamentos aos portadores do HIV e doentes de AIDS. Disponível em: http://www.planalto.gov.br/ccivil_03/leis/19313.htm. Acesso em: 20 maio 2019.

BRASIL. Lei $n^{\mathbf{0}}$ 13.979, de 6 de fevereiro de 2020. Dispõe sobre as medidas para enfrentamento da emergência de saúde pública de importância internacional decorrente do coronavírus responsável pelo surto de 2019. Disponível em: http://www.planalto.gov.br/ccivil_03/_ato2019-2022/2020/lei/L13979.htm. Acesso em: 20 abr. 2020.

BRASIL. Ministério da Saúde. Brasil distribui 22,9 milhões de comprimidos "3 em 1" nesta semana. 19 mar. 2018. Disponível em: http://www.aids.gov.br/pt-br/noticias/brasil-distribui229-milhoes-de-comprimidos-3-em-1-nesta-semana. Acesso em: 20 maio 2019.

BRASIL. Ministério da Saúde. Portaria MS no 886, de 24 de abril de 2007. Declara de interesse público os direitos de patente sobre o Efavirenz, para fins de concessão de licença compulsória para uso público não comercial. 2007. Disponível em: http://www.aids.gov.br/ptbr/legislacao/portaria-886-de-24-de-abril-de-2007. Acesso em: 20 maio 2019.

CAROTHERS, T. The rule of law revival. In: (Ed.). Promoting the rule of law abroad: in search of knowledge. Washington, D.C.: Carnegie Endowment for International Peace, 2006. 
DANTAS, Thomas K. S. Os limites constitucionais ao exercício do direito de patente e seus reflexos na indústria do petróleo, gás natural e biocombustíveis. Dissertação (Mestrado), Universidade Federal do Rio Grande do Norte (UFRN), Natal, 2014.

DAVIS, Kevin E.; TREBILCOCK, Michael J. The relationship between law and development: optimists versus skeptics. American Journal of comparative law. Salem (oregon): american society of comparative law, v. 56, n. 1, p. 895-946. 2008.

HERINGER, Astrid. Patentes farmacêuticas e propriedade industrial no contexto internacional. Curitiba: Juruá, 2001.

INSTITUTO NACIONAL DA PROPRIEDADE INTELECTUAL (INPI). Revista da Propriedade Industrial. Disponível em: http://revistas.inpi.gov.br/rpi/. Acesso em: 20 maio 2019.

KANG, Thomas H. Justiça e desenvolvimento no pensamento de Amartya Sen. Revista de Economia Política, vol. 31, no 3 (123), pp. 352-369, julho-setembro/2011.

MANKIW, N. Gregory. Introdução à economia. ed. 3. Pioneira Thomson Learning, 2005.

MENELL, P.; SCOTCHMER, S.. Intellectual Property Law. In: Polinsky, A.M., Shavell, S. (Eds), Handbook of Law \& Economics, v. 2, Amsterdam: Elsevier, 2007.

MENDES, M. O que é produtividade e como conseguir seu incremento? 2012. Disponível em http://www.brasil-economia-governo.org.br/2012/10/01/o-que-e-produtividade-e-comoconseguir-seu-incremento/. Acesso em: 20 maio 2019.

NOGUÉS, J. Patents and pharmaceutical drugs: understanding the pressures on developing countries. The World Bank. Working Paper Series 502. 1990. 41 p.

ORGANIZAÇÃO MUNDIAL DA PROPRIEDADE INTELECTUAL (OMPI). PCT Sistema Internacional de Patentes. Disponível em: https://www.wipo.int/pct/pt/index.html. Acesso em: 20 abr. 2020.

ORGANIZAÇÃO MUNDIAL DA PROPRIEDADE INTELECTUAL (OMPI). International Patent Classification (IPC). Disponível em: https://www.wipo.int/classifications/en/. Acesso em: 20 abr. 2020.

\section{PROGRAMA DAS NAÇÕES UNIDAS PARA O DESENVOLVIMENTO (PNUD). Relatório do Desenvolvimento Humano 2018. Disponível em: http://www.br.undp.org/content/brazil/pt/home.html. Acesso em: 20 maio 2019.}

RICARDO, David. Princípios de Economia Política e Tributação. Coleção "Economia Política”, ed. 1. São Paulo: Lebooks, 2018.

RODRIGUES, WCV; SOLER, O. Licença compulsória do efavirenz no Brasil em 2007: contextualização. Revista Panamericana de Salud Pública, v. 26, n. 6, p. 553-559. 2009. p. 555 .

SEN. Amartya. Desenvolvimento como liberdade. São Paulo: Companhia das Letras, 2010. 
SMITH. Adam. A riqueza das nações: das causas do aprimoramento das forcas produtivas do trabalho. Tradução de Maria Teresa Lemos De Lima, ed.1. v. 1. Curitiba: Editora Juruá, 2006.

TACHINARDI, Maria Helena. A guerra das patentes: o conflito Brasil x EUA sobre propriedade intelectual. Rio de Janeiro: Paz e Terra, 1993.

TAMANAHA, Brian Z. O primado da sociedade e as falhas do direito e desenvolvimento. Revista Direito GV, v. 6(1), p. 175-212, São Paulo, 2010. Disponível em: http://www.scielo.br/pdf/rdgv/v6n1/10.pdf. Acesso em: 20 maio 2019.

TRUBEK, David M.; GALANTER, Marc. Acadêmicos auto-alienados: reflexões sobre a crise norte-americana da disciplina "direito e desenvolvimento", in: O novo direito e desenvolvimento: presente, passado e futuro. Textos selecionados de David M. Trubek. São Paulo: Saraiva, 2009.

TRUBEK, David M.; SANTOS, A. (Ed.). The new law and economic development: a critical appraisal. United Kingdom: Cambridge University Press, 2006. 319 p. 